\title{
Financiarización urbana y burbuja del alquiler en España: tendencias y contrastes en perspectiva multiescalar
}

\author{
Ricardo Méndez Gutiérrez del Valle \\ Universidad Complutense de Madrid. Departamento de Geografía \\ ricardo.mendezgv@gmail.com
}

Recibido: junio de 2020

Aceptado: octubre de 2020

Publicado: abril de 2021

\section{Resumen}

La evolución reciente de las ciudades españolas está condicionada por la creciente atracción del capital financiero hacia la inversión inmobiliaria. Tras la burbuja de precios producida a comienzos de siglo, que tuvo como soporte el crédito hipotecario, y cuyo estallido provocó una profunda crisis, desde 2013 se inició un nuevo ciclo inmobiliario que incluye la reactivación del mercado de alquiler, generadora de fuertes contradicciones sociales y espaciales. El texto analiza la evolución reciente de la vivienda en alquiler y de sus precios, así como sus fuertes desigualdades espaciales a diferentes escalas, interpreta los principales factores de la reactivación, con especial protagonismo de nuevos actores financieros, y destaca su importancia actual como modo de extracción de rentas y factor de exclusión residencial.

Palabras clave: financiarización; ciclos inmobiliarios; mercado de alquiler; desigualdades urbanas

Resum. Financiarització urbana i bombolla del lloguer a Espanya: tendències i contrastos en perspectiva multiescalar

L'evolució recent de les ciutats espanyoles està condicionada per la creixent atracció de capital financer cap a la inversió immobiliària. Després de la bombolla de preus produïda al començament de segle, causada per l'expansió del crèdit hipotecari, i l'esclat de la qual va provocar una profunda crisi, des de 2013 es va iniciar un nou cicle immobiliari que inclou la reactivació del mercat de lloguer, generadora de fortes contradiccions socials i espacials. El text analitza l'evolució recent de l'habitatge de lloguer i dels seus preus, així com les seves fortes desigualtats espacials a diferents escales, interpreta els principals factors de la reactivació, amb especial protagonisme de nous actors financers, i destaca la seva importància actual com a via d'extracció de rendes i factor d'exclusió residencial.

Paraules clau: financiarització; cicles immobiliaris; mercat de lloguer; desigualtats urbanes 
Résumé. Financement urbain et bulle de location en Espagne : tendances et contrastes dans une perspective multiscalaire

L'évolution récente des villes espagnoles est conditionnée par l'attraction croissante du capital financier vers l'investissement immobilier. Après la bulle des prix au début du siècle, qui a été soutenue par le crédit hypothécaire et dont l'éclatement a provoqué une crise profonde, un nouveau cycle immobilier a commencé depuis 2013 qui comprend la réactivation du marché locatif, générant de fortes contradictions sociales et spatiales. Le texte analyse l'évolution récente du logement locatif et ses prix, ainsi que ses fortes inégalités spatiales à différentes échelles ; il interprète les principaux facteurs de la réactivation, avec une attention particulière de la part de nouveaux acteurs financiers, et souligne leur importance actuelle comme moyen de facteur d'extraction de revenus et d'exclusion résidentielle.

Mots-clés : financiarisation ; cycles immobiliers ; marché locatif ; inégalités urbaines

Abstract. Urban financialization and the rental bubble in Spain: Trends and contrasts from a multi-scale perspective

The recent evolution of Spanish cities has been conditioned by the growing attraction of financial capital towards real estate investment. In the upward cycle at the beginning of the century, the main driver was the expansion of mortgage credit. The bursting of this bubble led to the deep crisis of the last decade. After 2013, a new real estate cycle began that was also related with the reactivation of the rental market, producing intense social and spatial inequalities. This article analyzes the recent evolution of rental housing and rental prices, as well as these strong spatial inequalities at different scales. The main factors of the reactivation, particularly the new financial players, are then interpreted. Finally, the role of the current expansion of residential rentals as a mode of income extraction and a factor of residential exclusion is analyzed.

Keywords: financialization; real estate cycles; rental market; urban inequalities

\section{Sumario}

1. Introducción: objetivos, metodología y fuentes

2. Contexto teórico: financiarización urbana y nuevo ciclo inmobiliario

3. De la reactivación inmobiliaria a la expansión de la vivienda en alquiler
4. ¿Burbuja del alquiler?: una perspectiva interurbana

5. Alquileres en Madrid: un mapa de contrastes

6. Algunas conclusiones

Referencias bibliográficas

\section{Introducción: objetivos, metodología y fuentes}

La evolución reciente de las ciudades españolas se ve condicionada por un proceso de financiarización que, entre otras dimensiones, supone un creciente interés del capital financiero por la inversión inmobiliaria. A la burbuja de precios producida a comienzos de siglo, que tuvo como soporte el crédito hipotecario concedido de forma masiva por bancos y cajas (Naredo, 2009; 
Vinuesa, 2013), le siguió una profunda crisis provocada por su estallido, con importantes efectos de desposesión social y desigual intensidad según el grado de vulnerabilidad urbana. Pero desde 2013 se ha iniciado la fase expansiva de un nuevo ciclo inmobiliario, que incluye el crecimiento de la construcción y la compraventa de viviendas, junto con incrementos en los precios de venta y, más aún, de alquiler, impulsados principalmente por nuevos operadores financieros y generadores de fuertes contrastes socioespaciales (Méndez, 2019).

Tras una prolongada atonía desde mediados del siglo pasado, en un periodo dominado por los estímulos a la compra de vivienda y la construcción de una «sociedad de propietarios» (López y Rodríguez, 2010), la proporción de población que en España reside en viviendas de alquiler ha experimentado un crecimiento significativo desde hace más de una década. Aumenta así su importancia relativa dentro del mercado residencial español, si bien con notables diferencias según grupos sociales y áreas urbanas. Esa reactivación se ha acompañado por un rápido encarecimiento del precio de los alquileres, que en algunas ciudades y en determinados barrios de las grandes metrópolis evidencia la aparición de procesos especulativos que en el pasado reciente se vincularon casi en exclusiva a los precios de venta y que han resucitado el concepto de burbuja, asociada ahora a esta forma de tenencia y discutida por otros autores (García Montalvo, 2019).

El resultado ha sido un agravamiento del estrés residencial que padecen algunos colectivos, obligados a destinar una parte significativa de sus ingresos al pago de la renta, con la consiguiente aparición de movimientos sociales urbanos que han puesto en marcha acciones de resistencia frente a los masivos procesos de desposesión que se siguen produciendo en nuestras ciudades y que ahora tienen al impago del alquiler como causa principal (Palomera, 2019). Por todo ello, la vivienda en alquiler se convierte en objeto de investigación relevante, como uno de los ámbitos donde mejor se manifiesta la actual reconfiguración de los espacios urbanos en este nuevo ciclo de acumulación, construido sobre los escombros dejados por la Gran Recesión, que tuvo sus cimientos en los ámbitos financiero e inmobiliario. Ese binomio sigue manteniendo estrechos vínculos en la actualidad, pues la creciente atracción del capital por la inversión inmobiliaria constituye una de las principales expresiones de esta era de capitalismo global, neoliberal y financiarizado, que encuentra en las áreas urbanas — sobre todo en las de mayor tamaño - su máxima expresión y también sus principales contradicciones, al tiempo que refuerza el carácter de mercancía otorgado a la vivienda y al territorio en su conjunto (Aalbers, 2016; Mattos, 2018; Méndez, 2018). Se trata, pues, de una temática que aúna las aportaciones de la geografía económica y la geografía urbana en la búsqueda de una mejor comprensión del proceso y de su lógica espacial, así como para dar respuesta a una demanda social creciente, tal como se puso de manifiesto en la solicitud de ayudas al pago del alquiler - y no solo de las hipotecas - al estallar la pandemia provocada por la COVID-19, que ha provocado la momentánea detención del proceso que aquí se analiza.

Con este contexto, el objetivo central del artículo es analizar la evolución reciente de la vivienda de alquiler en las ciudades españolas, identificar su 
desigual importancia según territorios y las notables diferencias en el incremento de sus precios a diferentes escalas, así como algunas de sus consecuencias sociales más negativas. Pero, de forma especial, se pretende participar en el debate sobre las claves explicativas de su rápido encarecimiento en determinados espacios y cuestionar las interpretaciones que fijan su atención en el simple desajuste entre una oferta escasa y una demanda en expansión, para destacar el protagonismo de nuevos actores financieros cuyas estrategias no pueden ignorarse, así como la competencia de otros usos en determinados enclaves urbanos.

Para dar respuesta a tales objetivos, el texto propone un apartado teórico inicial sobre la necesidad de incorporar el concepto de financiarización a los actuales estudios urbanos y, en particular, sus vínculos con las dinámicas inmobiliarias, así como el significado de unos inversores institucionales que han cobrado creciente importancia como arrendatarios en los últimos años. Se analiza a continuación la reactivación del mercado de alquiler residencial en España y sus notables desigualdades espaciales a diferentes escalas, para descender por último a lo ocurrido en la ciudad de Madrid, que resulta un excelente laboratorio para comprender el auge del alquiler como mecanismo de extracción de rentas. El texto finaliza con unas conclusiones breves, sin profundizar en un debate sobre alternativas que desborda las posibilidades de este artículo.

Con relación a las fuentes, la dificultad que supone para un estudio detallado y territorializado de la vivienda en alquiler la ausencia de una estadística oficial con desagregación espacial exige combinar varias alternativas, resumidas en el Boletín sobre alquiler residencial que, desde 2017, publica el Observatorio de Vivienda y Suelo del Ministerio de Fomento (OVS, 2019). Están, por un lado, la Encuesta de condiciones de vida (INE) y la Encuesta financiera de las familias (Banco de España), que permiten identificar la importancia relativa, evolución y características de los residentes, mientras que la situación del parque de vivienda en alquiler puede aproximarse a partir de la Encuesta continua de hogares (INE) y, sobre todo, de la estadística que elabora para sus informes el OVS a partir de la Agencia Tributaria y la Dirección General del Catastro, que permite una desagregación provincial y para municipios con más de 25.000 habitantes. En todos estos casos, los datos disponibles al redactar estas páginas alcanzan hasta el año 2018.

Con relación al precio, un aspecto de particular interés en este caso, resulta habitual la utilización de los precios de oferta que recogen diversos portales inmobiliarios (Idealista, Fotocasa, Gesvalt), pues la única alternativa son los registros administrativos con que cuentan una parte de las comunidades autónomas, que recogen información sobre los depósitos de fianza por parte de los arrendadores, con resultados que coinciden con los anteriores en las tendencias que identifican, aunque no en las cifras, generalmente inferiores. El hecho de que esa información sobre fianzas no exista para 19 de las 50 provincias justificó usar aquí los datos del portal idealista.com disponibles hasta diciembre de 2019, por ser los que ofrecen una mayor desagregación espacial. Por ello, han sido utilizados también en informes del Ministerio y del Banco de España, pese a que puedan introducir cierta sobrevaloración sobre los precios 
de mercado efectivos. Para la ciudad de Madrid, esa información se contrastó con diversos indicadores a escala de distrito obtenidos de la base de datos que elabora el Servicio de Estadística del Ayuntamiento de Madrid para establecer posibles asociaciones espaciales.

\section{Contexto teórico: financiarización urbana y nuevo ciclo inmobiliario}

El mundo ha conocido en las últimas décadas un proceso de expansión financiera sin precedentes, que ha acentuado el poder de las finanzas no solo en el ámbito económico, sino también en la acción de los gobiernos, las dinámicas urbanas y la vida cotidiana de los ciudadanos. Esa posición hegemónica del capital financiero, así como la difusión de su lógica de funcionamiento, genera impactos múltiples sobre las sociedades y sus territorios. Esto ha difundido las referencias a la existencia actual de un régimen de acumulación financiarizado o un proceso de financiarización que resulta indisociable de la progresiva imposición de una racionalidad neoliberal que desregula numerosos mercados —en especial los de capital_, la globalización de muchos de ellos, o la masiva aplicación de las tecnologías digitales para acelerar los intercambios y densificar esas redes de flujos (Chesnais, 2003; Lapavitsas, 2016; Pike y Pollard, 2010; Christopherson et al., 2013).

Al mismo tiempo, este capitalismo financiarizado tiene su propia geografía, pues tanto las estrategias de las diferentes entidades financieras como el trazado que siguen los movimientos del capital muestran comportamientos espaciales muy selectivos, con las áreas urbanas —en especial las de mayor tamañocomo principales centros donde se acumula, gestiona e invierte ese capital (Méndez, 2018). En consecuencia, comprender mejor la evolución de las diferentes ciudades, su desigual capacidad de crecimiento, sus crisis y los procesos de desposesión que las acompañan, así como buena parte de las transformaciones morfológicas o funcionales recientes, exige hoy prestar mayor atención a factores y actores de carácter financiero para complementar la referencia a otro tipo de claves interpretativas más habituales en los estudios urbanos.

\subsection{Finanzas e inmobiliario: una atracción mutua}

Entre las diversas manifestaciones de esa influencia, destaca, en especial, la creciente atracción del capital financiero hacia el negocio inmobiliario, una tendencia ahora común a numerosos países, entre los que España ocupa un lugar destacado desde hace décadas. De este modo, «la vivienda y los bienes inmuebles urbanos se han convertido en producto de elección para el sector financiero corporativo, una caja de depósitos para los ricos, un depósito de capital y del exceso de liquidez de los mercados emergentes y un lugar conveniente para que las empresas ficticias guarden su dinero con muy poca transparencia» (Farha, 2017: 10). Una inversión inmobiliaria mundial que alcanzó los 435.000 millones de dólares en 2017 -lo que supone la mayor cifra registrada y supera en un 30\% la inversión realizada en 2013 - y un cre- 
cimiento del precio medio de la vivienda del $20 \%$ en los cinco últimos años y del $63 \%$ desde comienzos de siglo son sus principales exponentes (Fondo Monetario Internacional, 2019).

Sin negar la influencia que sobre la actividad inmobiliaria y los precios de venta o alquiler de las viviendas ejerce el incremento de la demanda, que puede asociarse al aumento de la población y del número de hogares, el empleo o los ingresos por habitante, esta interpretación resulta insuficiente para justificar esa tendencia expansiva. Por el contrario, no puede ignorarse que el capital es el combustible esencial que pone en marcha la máquina del crecimiento urbano y, por tanto, las estrategias de los actores financieros — que son sus principales proveedores - resultarán esenciales para la mejor comprensión de esa progresiva «urbanización del capital» (Christophers, 2011). Para este tipo de operadores, el suelo y la vivienda se convierten en un activo más del que extraer beneficios, lo que contribuye a la creciente mercantilización de una ciudad entendida como negocio, en detrimento de su función social como espacio para habitar y relacionarse, lo que la somete de forma creciente al «imperio de los mercados» (Theodore et al., 2009).

La explicación más consistente de esa creciente simbiosis entre finanzas e inmobiliario fue propuesta por Lefebvre en sus obras sobre la revolución urbana y la producción del espacio (1970 y 1974) mediante la teoría del «segundo circuito de acumulación", reformulada más tarde por Harvey (1985) y recogida luego por otros autores (Fox Gotham, 2013; Aalbers, 2016; Lois et al., 2016; Rolnik, 2018; Mattos, 2018), lo que hace innecesario desarrollar aquí con amplitud ese argumento. Basta recordar tan solo la idea de que las sociedades capitalistas avanzadas se enfrentan a la contradicción que supone la necesaria reinversión de los excedentes generados para mantener la acumulación de capital, frente a la tendencia estructural a reducir las plusvalías obtenidas en el circuito primario (producción, intercambio y distribución de bienes y servicios), como fruto de la creciente competencia interempresarial y la imposibilidad de que el consumo absorba una producción en constante aumento ante las deficiencias en los mecanismos distributivos, que la imposición de una racionalidad neoliberal vino a acentuar.

Eso justificaría la reorientación de una parte creciente de esos excedentes de capital hacia un circuito secundario relacionado con la producción del espacio, lo que convierte a las áreas urbanas en general y al inmobiliario en particular en fuente esencial de acumulación de plusvalías. Su consecuencia es que «la vivienda y el desarrollo urbanístico no son en la actualidad fenómenos secundarios, sino que se están convirtiendo en algunos de los principales procesos que impulsan el capitalismo global contemporáneo» (Madden y Marcuse, 2018: 34), contando siempre con la importante contribución del Estado, mediante la liberalización de los mercados de capital, hipotecario o de suelo, el progresivo abandono de la producción de vivienda social frente al apoyo fiscal a su compra en el mercado libre, la progresiva desarticulación de la capacidad regulatoria del planeamiento urbanístico, la construcción de infraestructuras de soporte para poner en valor extensas superficies, capaces de atraer la voracidad de los agentes urbanizadores, etcétera. 


\subsection{Mercado de alquiler y actores financieros en el nuevo ciclo inmobiliario}

No obstante, la evolución de la inversión y la producción inmobiliaria, el volumen de transacciones y los precios de venta o alquiler de las viviendas están sometidos a oscilaciones cíclicas. Así, alternan periodos de fuerte expansión, cuando la abundancia de capital y la facilidad para obtener crédito favorecen la creación de burbujas especulativas, con momentos de crisis, cuando el riesgo acumulado por el sobreendeudamiento alcanza sus límites, suben los tipos de interés y se frena la concesión de crédito, lo que provoca una contracción que paraliza el mercado, devalúa los inmuebles y expulsa de sus viviendas a quienes no pueden pagar la deuda contraída. La actividad inmobiliaria se convierte así en «factor determinante y detonante de los ciclos de auge y recesión y de las crisis económicas» (Daher, 2013: 48).

En el caso de las ciudades españolas, tras la «década prodigiosa del urbanismo español» (Burriel, 2008), la profunda crisis desatada a partir de 2007 tocó fondo en el año 2013, para iniciarse una recuperación desde entonces visible en múltiples indicadores (Méndez, 2019). Pero cada ciclo tiene también características específicas y, por tanto, esta nueva fase expansiva no resulta una mera repetición de la registrada en 1996-2007, sino que presenta novedades sustanciales, entre las que deben considerarse dos de particular importancia para los objetivos planteados: la incorporación de nuevos operadores financieros e inmobiliarios que comparten con los tradicionales el negocio de la ciudad, y la dinamización del mercado de la vivienda en alquiler tras décadas de constante retroceso, con la aparición de fuertes fenómenos especulativos en este segmento que muestran diferencias inter e intraurbanas particularmente acusadas.

Es indudable que en el ciclo anterior los bancos y cajas de ahorros fueron protagonistas destacados mediante la expansión sin precedentes de un crédito hipotecario que se convirtió en parte esencial de su negocio. La competencia por captar clientes propició la difusión de estrategias hipotecarias de riesgo y un masivo endeudamiento de promotores inmobiliarios, familias y empresas, lo que acabó provocando el brusco final del proceso y una profunda crisis bancaria, que se saldó con la práctica desaparición de las cajas de ahorros y un proceso de concentración sin precedentes que ha reforzado el oligopolio bancario. Tras sanear sus balances, la banca española ha vuelto a impulsar desde 2013 la concesión de crédito para la promoción y compra de vivienda, con un aumento significativo del negocio hipotecario, aunque lejos aún de los niveles alcanzados al inicio del siglo.

Pero la principal novedad ahora radica en la mayor penetración del capital transnacional a través de diversos tipos de inversores institucionales, con especial protagonismo de los fondos de inversión, que se incorporaron al mercado inmobiliario español a partir de 2013 para concentrar buena parte de su actividad en las grandes áreas urbanas y espacios turísticos litorales, considerados más rentables y de menor riesgo. Se trata de sociedades dedicadas a la gestión colectiva de un capital procedente de particulares (desde grandes fortunas a pequeños inversores), bancos, empresas, fondos de pensiones, aseguradoras 
o instituciones públicas, que se dirige a la compra de productos financieros (acciones, bonos, derivados...), o bien a diferentes tipos de activos materiales, desde compañías integradas en múltiples sectores hasta suelo e inmuebles empresariales o residenciales. Su capacidad para comprar edificios enteros les ha convertido en pocos años en grandes propietarios, con una oferta territorialmente concentrada debido a su especial atracción hacia aquellos lugares que ofrecen seguridad y alta rentabilidad a corto plazo, de donde emigran con rapidez cuando se reducen los beneficios o aumentan los riesgos, mediante procesos de desinversión y capitalización de las plusvalías. Entre estos, resultan de particular importancia también aquellos especializados en la actividad inmobiliaria, que en el ámbito internacional se conocen como REIT (Real Estate Investment Trust) y en España como Socimi (Sociedades Cotizadas de Inversión en el Mercado Inmobiliario), dedicadas de forma específica al alquiler de inmuebles, de las que en apenas un sexenio se han creado un total de 72, de las que 22 se especializan en el alquiler de viviendas (Méndez, 2019). Según el informe anual de la European Public Real Estate Association, en 2019, España es el país europeo con mayor número de este tipo de sociedades, por delante del Reino Unido (55 sociedades) y Francia (30), aunque los 22.954 millones de euros de capitalización quedan muy por debajo de los 63.988 que representan en Alemania y los 51.040 de Francia, lo que pone de manifiesto la persistencia de cierto minifundismo (EPRA, 2019).

El rápido crecimiento de la actividad inmobiliaria llevada a cabo por estos fondos de inversión y, al menos en parte, por las Socimi tuvo lugar mediante la compra de grandes bolsas de suelo e inmuebles propiedad de bancos o de la Sareb, resultado de procesos de desahucio ejecutados a promotores o familias, que adquirieron muchas veces a precio de saldo. También se produjo por la adquisición de grandes promotoras preexistentes o la creación de otras nuevas, lo que les permite controlar buena parte de la oferta de vivienda nueva. Por último, creció también mediante la compra de viviendas sociales a gobiernos autonómicos o locales imbuidos del credo neoliberal, deseosos de hacer caja y con frecuentes connivencias con los gestores de esos fondos, con Madrid como principal ejemplo. En el caso de las Socimi, a todo eso se sumó un tratamiento fiscal favorable desde 2012, que las exime de pagar el impuesto de sociedades junto con una bonificación del $95 \%$ en el de transmisiones patrimoniales y actos jurídicos documentados (Vives-Miró y Rullán, 2014).

El resultado ha sido un trasvase masivo de propiedad en pocos años, que se hace especialmente patente en las más de 100.000 viviendas que se destinan al alquiler, con su máximo exponente representado por Blackstone, el mayor casero de España, que comenzó a invertir en aquí en 2012 y hoy concentra el 95\% de su oferta en la región metropolitana de Madrid (Gabarre, 2019: 52). Este proceso muestra también una elevada dependencia de la trayectoria, pues algunas características de la reactivación posterior a 2013 resultan una herencia del ciclo anterior y muestran la vigencia del concepto de «acumulación por desposesión», acuñado por Harvey (2007), para aludir a ese tipo de estrategias. La figura 1 propone una interpretación esquemática de esta red 
Figura 1. Actores en la reactivación de la vivienda en alquiler: una interpretación

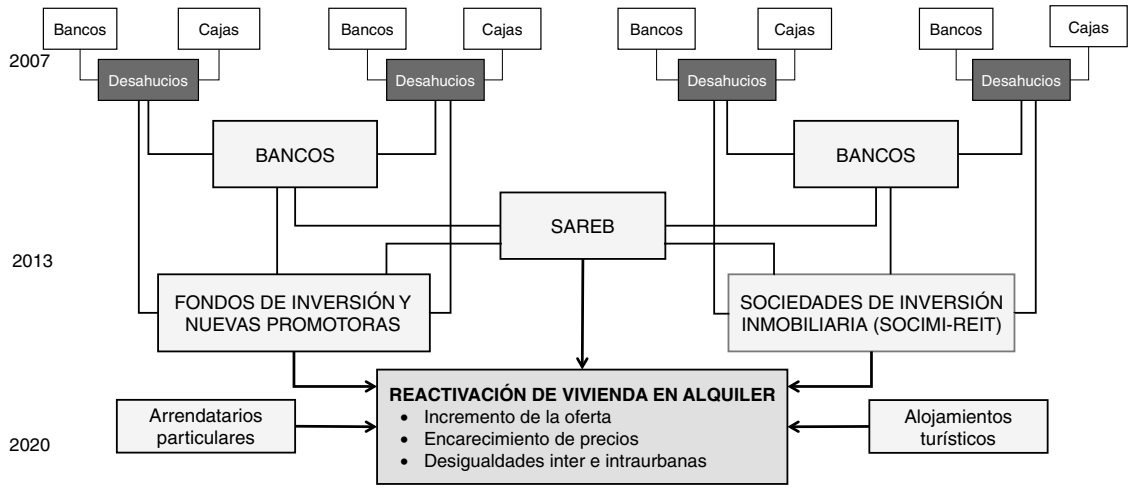

Fuente: elaboración propia.

de relaciones que subyace a la reactivación del mercado de alquiler residencial y al encarecimiento de los precios, un aspecto al que se han sumado los arrendatarios privados, beneficiados por el impulso alcista promovido por los grandes tenedores de vivienda, junto con la proliferación de alojamientos turísticos en espacios centrales de numerosas ciudades, que compiten por el uso del suelo en esas áreas.

En resumen, las páginas que siguen analizan el dinamismo reciente de la vivienda en alquiler, sus principales características, la evolución de sus precios y sus específicas pautas de distribución, como reflejo de las lógicas subyacentes a este nuevo ciclo inmobiliario. Esta investigación toma como punto de partida algunas publicaciones recientes sobre este mercado en España (Alves y Urtasun, 2019; García Montalvo, 2019; López Rodríguez y Matea, 2019; Gabarre, 2019), pero incide en su territorialización, en la influencia de los actores financieros y, al descender al ámbito intraurbano en el caso de Madrid, permite hacer algunas aportaciones al debate actual sobre las claves de la llamada burbuja del alquiler.

\section{De la reactivación inmobiliaria a la expansión de la vivienda en alquiler}

La recuperación de la actividad inmobiliaria en España se inició en 2013 y se ha consolidado desde entonces, tal como evidencian numerosos indicadores - disponibles en las Estadísticas de vivienda que publica en su web el Ministerio de Transportes, Movilidad y Agenda Urbana- que se contraponen a las tendencias recesivas del sexenio anterior. Si la inversión en vivienda creció un 48,6\% entre 2013-2019, la construcción volvió también a registrar una tendencia alcista, al aumentar tanto las viviendas terminadas $(65,5 \%)$ como, sobre todo, las iniciadas $(212,3 \%)$, pese a la persistencia de un amplio stock de vivienda vacía. Su contrapunto fue el retroceso de las viviendas protegidas y de precio tasado $(-61,2 \%)$ hasta cifras meramente testimoniales, al tratarse 
de una tendencia inherente a la gestión neoliberal de la ciudad. En paralelo, las ventas de vivienda casi se duplicaron $(89,0 \%)$ y el valor registrado de esas transacciones creció un $65,8 \%$, aunque menos de una décima parte del total correspondió a vivienda nueva, frente a la primacía de la de segunda mano, en buena medida fruto de los desahucios ejecutados por impago hipotecario y que pasaron a manos de bancos y sus promotoras, la Sareb, o fueron adquiridos por inversores institucionales para su posterior reingreso en el mercado.

Sin duda, estas tendencias no fueron ajenas a la reactivación del mercado hipotecario - tal como recoge la Estadística de hipotecas publicada por el INE a partir de los registros de la propiedad-, una vez saneados los balances de los bancos, con un incremento del $79,2 \%$ en el número de hipotecas constituidas (357.936 en 2019) y del $124 \%$ en su importe (44.733 millones de euros ese año).

Pero el cambio de tendencia más significativo corresponde a la vivienda en alquiler, que gana en importancia y acaba así con medio siglo de retroceso relativo como forma de tenencia. Según datos de la Encuesta de condiciones de vida del INE (tabla 1), los hogares que en 2007 residían en una vivienda en propiedad eran cuatro de cada cinco, mientras que la vivienda en alquiler representaba un 13,6\% y la cesión gratuita sumaba el 6,3\% restante. El estallido de la crisis paralizó el crédito y la compra de vivienda, por lo que en 2013 esa proporción del alquiler había aumentado $(15,4 \%)$, pero la posterior recuperación no cambió la tendencia (17,5\% en 2018), con lo que los hogares que viven ahora en alquiler superan los tres millones y medio. Lo esencial de ese crecimiento corresponde a las viviendas a precio de mercado (14,8\% del total), frente al constante retroceso de las que pagan rentas inferiores al precio inferior por contar con algún tipo de protección $(2,7 \%)$, lo que agrava la tradicional anemia del parque de vivienda pública en arrendamiento.

Según el OVS (2019), ese incremento se ha producido, sobre todo, en las grandes áreas urbanas y los litorales turísticos, donde se alcanzan las tasas más elevadas. De este modo, el alquiler a precio de mercado supera el $20 \%$ de las viviendas en Baleares, Cataluña y Madrid, mientras que en volumen absoluto las provincias de Madrid (509.083) y Barcelona (474.550) suman casi un millón de viviendas, y las mediterráneas comprendidas entre Gerona y Málaga otras 590.183, que con las 219.852 de las tres provincias insulares reúnen más de la mitad de las contabilizadas. A escala municipal, las ciudades de Madrid (312.970) y Barcelona (180.128) se sitúan a notable distancia del resto, con Valencia y Zaragoza también por encima de las 50.000 viviendas. En solo diez ciudades se concentra una quinta parte del total (788.267 viviendas).

Ese rápido aumento responde a la confluencia de diversos factores que han incrementado su demanda. Por una parte, el alquiler es la opción preferida por personas con elevada movilidad laboral, que no desean atarse al pago de una vivienda durante largos periodos de tiempo, con el segmento de profesionales jóvenes de alta cualificación como principal exponente. Pero la mayor parte de los que arriendan lo hacen más por necesidad que por voluntad, al enfrentar barreras de entrada para la compra debido a sus bajos ingresos o precariedad 
Tabla 1. Evolución del régimen de tenencia de la vivienda en España, 2007-2018 (\%)

\begin{tabular}{lccccc}
\hline Años & $\begin{array}{c}\text { Vivienda en } \\
\text { propiedad }\end{array}$ & $\begin{array}{c}\text { Alquiler a precio } \\
\text { mercado }\end{array}$ & $\begin{array}{c}\text { Alquiler a precio } \\
\text { inferior }\end{array}$ & $\begin{array}{c}\text { Cesión } \\
\text { gratuita }\end{array}$ & Alquiler + cesión \\
\hline 2007 & 80,1 & 10,4 & 3,2 & 6,3 & 19,9 \\
2013 & 77,7 & 12,9 & 2,5 & 6,9 & 22,3 \\
2018 & 76,1 & 14,8 & 2,7 & 6,4 & 23,9 \\
\hline
\end{tabular}

Fuente: INE. Encuesta de condiciones de vida.

laboral, lo que les excluye del acceso al crédito hipotecario. Según esa fuente, la vivienda en alquiler tiene mayor presencia entre los grupos sociolaborales de riesgo. Sobre un promedio del $17,5 \%$ - que asciende al 19,3\% en el caso de la mujer-, el alquiler alcanza un $52,4 \%$ entre los jóvenes con menos de 30 años, el 58,9\% entre los extranjeros procedentes de la Unión Europea y hasta el 77,3\% si lo hacen del resto del mundo. En cuanto al nivel de ingresos según Eurostat, el alquiler - junto con la cesión gratuita en este caso- tiene una presencia moderada $(17,3 \%)$ entre los hogares que superan el $60 \%$ de la renta media, frente al $43,3 \%$ en el resto. Por esa razón, su rápido encarecimiento se convierte para una parte de la población en causa de estrés residencial, cuando no de exclusión.

Los datos disponibles sustentan la aparición en los últimos años de una burbuja del alquiler, si se entienden las burbujas como episodios de fuertes y sostenidas alzas de precios de ciertos activos, no explicables por las condiciones del mercado. Según la base de datos del portal inmobiliario Idealista, en diciembre de 2006 el precio medio de oferta se situaba en 8,8 euros $/ \mathrm{m}^{2}$, pero el impacto de la crisis y las políticas de austeridad lo redujo a 7,2 euros al finalizar 2013. A partir de esa fecha, la reactivación del sector inmobiliario se reflejó de forma moderada hasta 2015, para iniciar desde entonces una escalada que alcanza los 10,9 euros en diciembre de 2019. Eso equivale a un encarecimiento del $45,3 \%$ en los últimos cuatro años (figura 2 a) y sitúa su precio medio muy por encima del anterior a la crisis, lo que no ocurre con el de venta. Así, se pone en evidencia su creciente importancia como forma de extracción de rentas en un contexto de elevadas dificultades para el acceso a la propiedad de amplios sectores sociales. No obstante, la evolución interanual del precio confirma cierta moderación en el último año $(4,8 \%)$, pues la desaceleración general de la economía y unos niveles excesivos en las grandes ciudades plantean crecientes dificultades a la población más vulnerable, lo que evidencia los límites que enfrentan incrementos de precio ajenos a toda racionalidad.

Se trata de un fenómeno especulativo aún más evidente, si se compara la evolución de los alquileres y los precios de venta con la evolución de los salarios reales, según la Encuesta trimestral de coste laboral del INE (figura 2b). Mientras que estos últimos crecieron poco más de un 3\% desde 2013, los precios de venta lo hicieron en promedio un $20 \%$ y los del alquiler casi un $50 \%$. La intensificación del esfuerzo para acceder a una vivienda a que se enfrentan los 
Figura 2. Evolución del precio del alquiler, venta de vivienda y salarios reales, 2006-2019

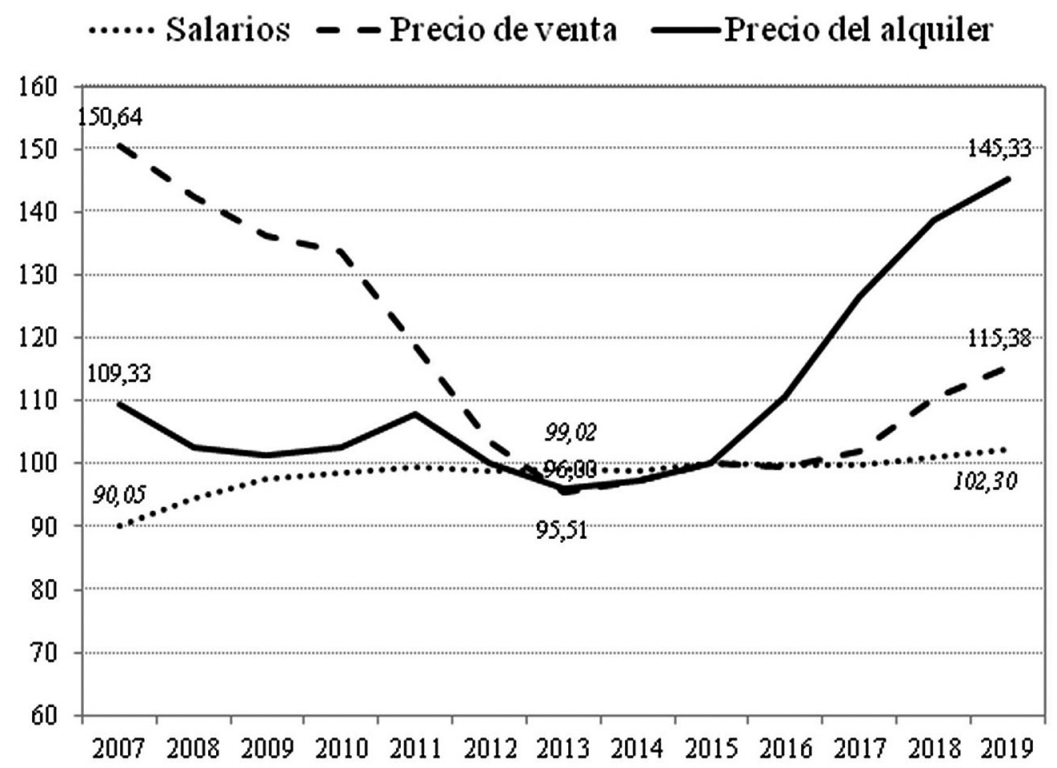

Fuente: idealista.com, Instituto Nacional de Estadística y elaboración propia.

arrendatarios tiene como consecuencia directa un aumento de los desahucios derivados del impago de los alquileres, que se convierten así en predominantes como forma de desposesión, al tomar el relevo a los que con anterioridad se derivaban del impago de las hipotecas.

Según datos de la Estadística judicial, que publica el Consejo General del Poder Judicial, los lanzamientos recibidos en los servicios comunes del TSJ sumaron 708.292 entre enero de 2008 y el tercer trimestre de 2019. Por su parte, los lanzamientos practicados por los juzgados de primera instancia desde el inicio de la reactivación en 2013 alcanzan los 426.593 hasta el tercer trimestre de 2019 (173 por día), de los que 243.968 (57,2\%) lo fueron en aplicación de la Ley de Arrendamientos Urbanos, frente a 162.258 (38,0\%) por ejecución hipotecaria, y el resto (20.367) por otras causas. Esa primacía de los desahucios por impago del alquiler se refuerza con el paso del tiempo: representaron el $52,9 \%$ del total en 2014, pero alcanzaron ya el 66,6\% en los tres primeros trimestres de 2019.

\section{4. ¿Burbuja del alquiler?: una perspectiva interurbana}

La reactivación del mercado de vivienda en alquiler y la paralela subida de precios son procesos consolidados, pero sometidos a fuertes contrastes espaciales que acentúan la segmentación del territorio basada en una lógica mercantil, cualquiera que sea la escala de análisis utilizada. Pese a basarse en simples 
Figura 3. Distribución provincial de precios del alquiler 2019 y evolución 2013-2019

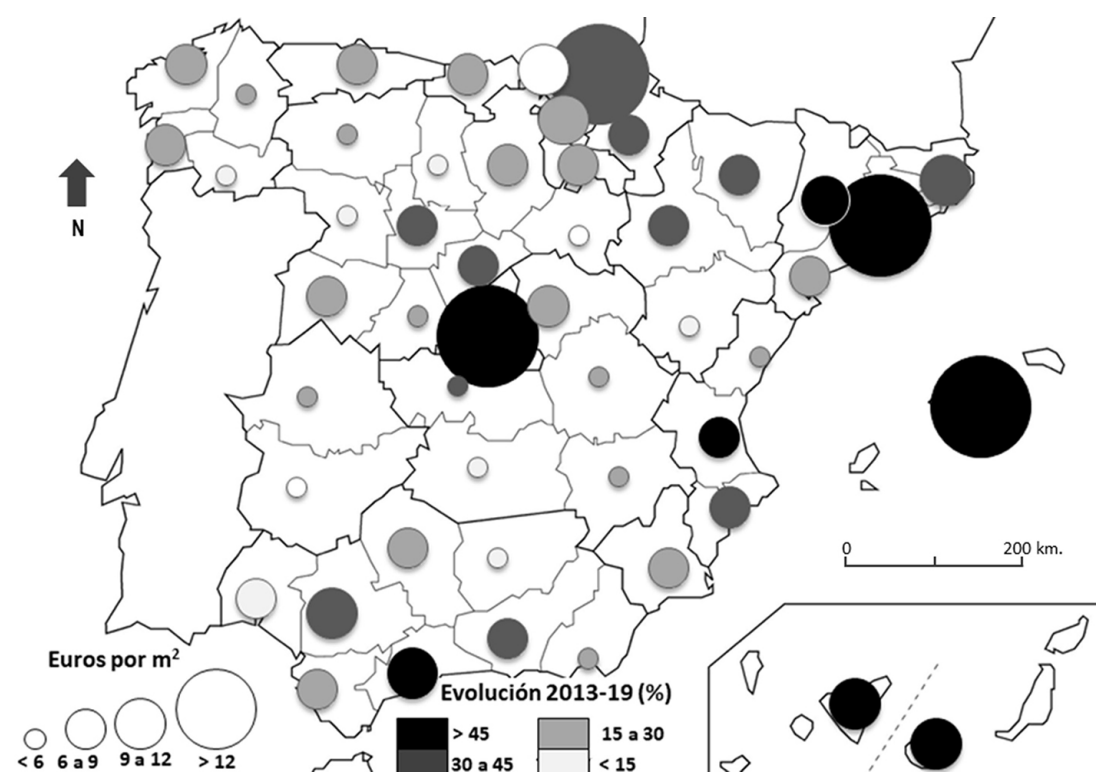

Fuente: idealista.com y elaboración propia.

promedios estadísticos que ocultan importantes diferencias internas, el mapa provincial ofrece ya una visión sintética de esas tendencias y sus principales desequilibrios (figura 3).

En diciembre de 2019, los precios medios de alquiler en Barcelona $\left(14,9\right.$ euros $\left./ \mathrm{m}^{2}\right)$ y Madrid $(14,7)$ superan ampliamente los del resto, con valores elevados en las provincias con mayores ingresos por habitante, que cuentan con mercados de vivienda más dinámicos. En una situación opuesta se encuentran provincias interiores de las dos Castillas, Aragón, Galicia, Extremadura y Andalucía, aquejadas por una mayor atonía, aún por debajo de los 6 euros $/ \mathrm{m}^{2}$, al igual que Castellón o Almería. Pero lo ocurrido en el último sexenio de recuperación económica ha extremado esa desigualdad, pues, frente a un encarecimiento que supera el 50\% en las islas Baleares, Las Palmas, Santa Cruz de Tenerife, Barcelona, Valencia, Málaga, Madrid o Lérida, otras diez provincias no alcanzaron aumentos del 15\%, con la práctica estabilización de precios en algunas de ellas. Esa reactivación a diferentes velocidades contrapone, pues, la fuerte subida de precios en las provincias con grandes áreas urbanas y turísticas a un crecimiento muy moderado en territorios interiores que pierden población, pero también en provincias del litoral atlántico poco implicadas en los ciclos inmobiliarios de estas últimas décadas.

Si Burriel (2014: 106) afirmó que el mapa de la crisis era prácticamente el negativo del anterior mapa de la burbuja, ahora vuelve a serlo del de la reactivación, con el alquiler como una de sus principales manifestaciones, tal como 
Tabla 2. Precios extremos del alquiler y tasas de crecimiento: municipios $>25.000$ habitantes

\begin{tabular}{lclc}
\hline Municipio & $\begin{array}{c}\text { Valores máximos } \\
\text { (diciembre 2019) }\end{array}$ & Municipio & $\begin{array}{c}\text { Máximo aumento } \\
\text { 2013-2019 (\%) }\end{array}$ \\
\hline Ibiza & 17,4 & Granadilla de Abona & 76,92 \\
Barcelona & 16,5 & Estepona & 70,91 \\
Santa Eulalia del Río & 16,4 & Manacor & 70,59 \\
Madrid & 16,1 & Arrecife & 68,00 \\
S. Bartolomé Tirajana & 15,3 & Santa Eulalia del Río & 64,00 \\
San Sebastián & 14,7 & Puerto del Rosario & 61,36 \\
Gavá & 14,6 & Arona & 60,27 \\
San Adrián de Besós & 14,5 & Inca & 60,00 \\
Castelldefels & 14,4 & Ibiza & 59,63 \\
Calviá & 13,6 & Gavá & 56,99 \\
\hline & Valores mínimos & & Mínimo aumento \\
Municipio & (diciembre 2019) & Municipio & 2013-2019 (\%) \\
\hline Narón & 4,5 & S. Andrés del Raba- & 4,08 \\
Lucena & 4,4 & nedo & 4,04 \\
Puertollano & 4,2 & Lejona & $-4,12$ \\
Tomelloso & 4,0 & Santurce & $-4,55$ \\
\hline Elda & & Melilla & \\
\hline
\end{tabular}

Fuente: idealista.com y elaboración propia.

se constata cuando se aproxima la lente al ámbito urbano. Con la información disponible en el portal inmobiliario aquí utilizado como fuente, puede compararse la evolución de los precios de oferta durante el sexenio 2013-2019 en 220 municipios urbanos con más de 25.000 habitantes, frente a 63 que no cuentan con esa información por la escasez de transacciones realizadas (tabla 2).

Como espacios privilegiados para la atracción de capital, así como de grupos socio-profesionales cualificados y de altos ingresos, las metrópolis de Barcelona y Madrid superan los 16 euros $/ \mathrm{m}^{2}$, tal como también ocurre en los municipios turísticos de Santa Eulalia del Río e Ibiza. Valores también elevados se registran en otras grandes ciudades (San Sebastián, Bilbao), pero son más numerosos los núcleos turísticos insulares y algunos de los situados en entornos metropolitanos, sobre todo de Barcelona, que combinan ambas funciones. En el extremo opuesto, pequeñas ciudades que han padecido intensos procesos de desindustrialización, como Linares, Narón, Lucena, Puertollano o Tomelloso, no superan los 4,5 euros $/ \mathrm{m}^{2}$, con Elda $(3,7)$ como máximo exponente de un declive que pone en cuestión el modelo productivo de las últimas décadas. El diagrama de la figura 4, que relaciona precios y tasas de crecimiento, permite esquematizar una sencilla tipología al identificar aquellos municipios urbanos que superan los respectivos promedios y una desviación típica. 
Figura 4. Precios de alquiler y evolución 2013-2019 en municipios con más de 25.000 hab.

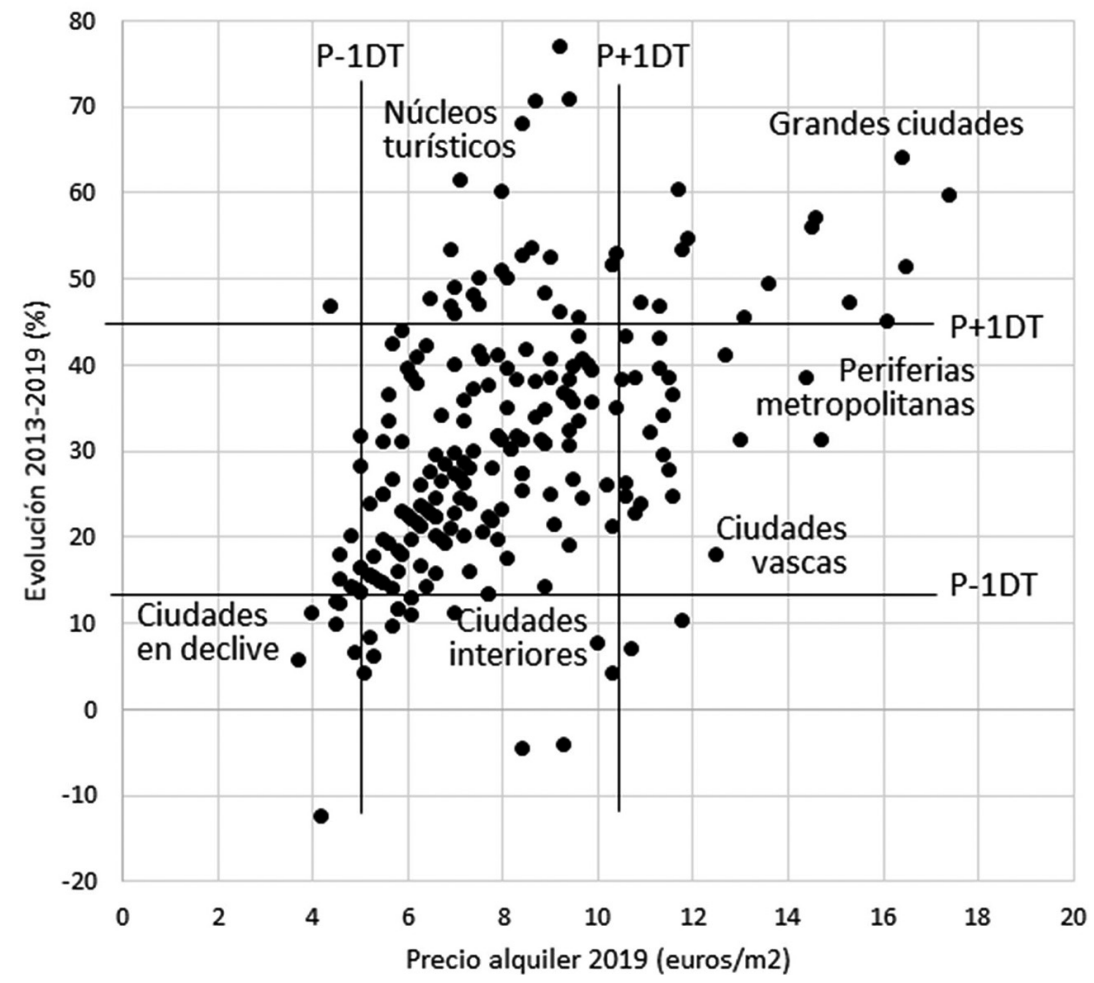

Fuente: idealista.com y elaboración propia.

Cuando se considera la evolución de esos precios en el último sexenio, se hacen más evidentes unos procesos especulativos con fuerte selectividad espacial, que alcanzan tasas de crecimiento superiores al $70 \%$ en los núcleos turísticos de Granadilla de Abona, Estepona y Manacor, mientras 15 de los 20 municipios con mayores incrementos tienen esa misma especialización funcional y superan incluso a las grandes ciudades. Como contrapunto, los alquileres aumentaron por debajo del 6\% en Ciudad Real, Elda, San Andrés del Rabanedo y Lejona, incluso con valores negativos en Santurce, Melilla o Puertollano. Pero es en la escala intraurbana donde pueden obtenerse resultados de mayor interés para entender las claves que justifican tales contrastes, al correlacionar las tendencias del alquiler con diferentes indicadores socioeconómicos.

\section{Alquileres en Madrid: un mapa de contrastes}

Como ciudad de mayor tamaño dentro del sistema urbano español, Madrid resulta un exponente destacado de las relaciones asimétricas entre propietarios y 
Tabla 3. Precios de alquiler y venta de viviendas en los distritos de Madrid, 2013-2019

\begin{tabular}{|c|c|c|c|c|c|c|}
\hline Distrito & $\begin{array}{l}\text { Precio alquiler } \\
\text { dic.-2019 } \\
\text { (euros } / \mathrm{m}^{2} \text { ) }\end{array}$ & $\begin{array}{c}\text { Evolución } \\
\text { alquiler } \\
\text { 2013-2019 (\%) }\end{array}$ & $\begin{array}{l}\text { Evolución } \\
\text { alquiler } \\
\text { 2013-2016 (\%) }\end{array}$ & $\begin{array}{c}\text { Evolución } \\
\text { alquiler } \\
\text { 2016-2019 (\%) }\end{array}$ & $\begin{array}{c}\text { Evolución } \\
\text { precio venta } \\
\text { 2013-2019 (\%) }\end{array}$ & $\begin{array}{l}\text { Evolución del } \\
\text { precio de } \\
\text { alquiler/venta (\%) }\end{array}$ \\
\hline Arganzuela & 15,80 & 45,14 & 23,74 & 17,30 & 49,85 & 90,56 \\
\hline Barajas & 11,70 & 14,91 & 3,86 & 10,64 & 25,83 & 57,72 \\
\hline Carabanchel & 12,00 & 36,18 & 18,41 & 15,02 & 27,22 & 132,93 \\
\hline Centro & 18,70 & 39,74 & 32,22 & 5,69 & 56,14 & 70,78 \\
\hline Chamartín & 16,30 & 32,83 & 14,81 & 15,69 & 29,44 & 111,50 \\
\hline Chamberí & 18,10 & 39,19 & 33,21 & 4,49 & 46,60 & 84,10 \\
\hline Ciudad Lineal & 13,50 & 32,13 & 19,66 & 10,42 & 22,18 & 144,84 \\
\hline Fuencarral-El Pardo & 12,60 & 27,54 & 15,58 & 10,34 & 26,52 & 103,83 \\
\hline Hortaleza & 12,30 & 12,86 & 6,49 & 5,99 & 28,60 & 44,98 \\
\hline Latina & 12,40 & 46,66 & 23,12 & 19,12 & 37,67 & 123,87 \\
\hline Moncloa-Aravaca & 14,60 & 28,52 & 26,76 & 1,39 & 29,98 & 95,12 \\
\hline Moratalaz & 11,20 & 34,45 & 16,66 & 15,25 & 32,51 & 105,95 \\
\hline Puente de Vallecas & 12,40 & 43,51 & 18,24 & 21,37 & 38,78 & 112,21 \\
\hline Retiro & 16,40 & 42,37 & 23,39 & 15,37 & 42,47 & 99,75 \\
\hline Salamanca & 18,90 & 42,18 & 25,71 & 13,10 & 46,39 & 90,92 \\
\hline San Blas-Canillejas & 11,90 & 28,20 & 14,40 & 12,06 & 14,79 & 190,64 \\
\hline Tetuan & 16,00 & 42,57 & 33,59 & 6,73 & 40,72 & 104,55 \\
\hline Usera & 11,90 & 34,57 & 10,30 & 22,01 & 27,98 & 123,57 \\
\hline Vicálvaro & 10,90 & 33,22 & 11,28 & 19,71 & 27,85 & 119,27 \\
\hline Villa de Vallecas & 11,30 & 29,19 & 10,71 & 16,69 & 23,10 & 126,36 \\
\hline Villaverde & 10,70 & 34,87 & 12,47 & 19,92 & 28,38 & 122,88 \\
\hline Madrid & 16,10 & 43,66 & 28,37 & 11,90 & 38,17 & 114,37 \\
\hline
\end{tabular}

Fuente: idealista.com y elaboración propia.

demandantes de vivienda, así como de las notables desigualdades espaciales que se suman a las sociales para construir un espacio urbano altamente fragmentado. Los más de 16 euros por metro cuadrado en diciembre de 2019 sitúan al municipio entre los más caros de España, y el 45\% de aumento registrado en el último sexenio también resulta uno de los más elevados, pero es al analizar la situación en sus 21 distritos cuando se hace evidente la lógica mercantil que guía el reparto de los precios, así como su reciente y desigual encarecimiento (tabla 3).

Los 18,7 euros $/ \mathrm{m}^{2}$ de promedio del distrito Centro, junto con los 18,9 de Salamanca o los 18,1 de Chamberí, en los sectores más valorados del Ensanche, casi duplican los menos de 11 euros de Villaverde o Vicálvaro. Al descender a los barrios, la brecha se hace más profunda, con los de Recoletos (Salamanca) y Trafalgar (Chamberí) por encima de los 20 euros $/ \mathrm{m}^{2}$, junto a Chueca-Justicia, Sol y Malasaña-Universidad (Centro) o Castellana y Goya (Retiro) en precios muy próximos. Su contrapunto son los 9,8 euros del barrio de San Fermín (Usera) y los poco más de 10 en Butarque y Los Ángeles (Villaverde), Rosas 
Figura 5. Precios de alquiler y evolución en los distritos de Madrid, 2013-2019

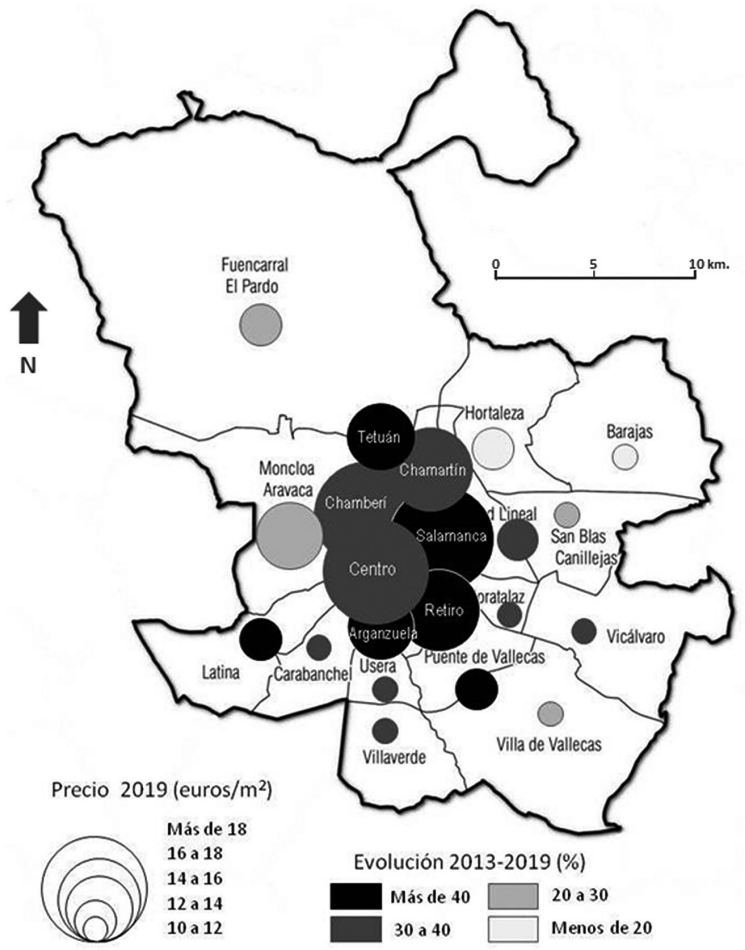

Fuente: idealista.com y elaboración propia.

(San Blas-Canillejas), Valdebernardo-Valderribas (Vicálvaro) o Buenavista (Carabanchel). Pervive así la tradicional divisoria que contrapone los espacios centrales a los periféricos y los del noroeste a los del sureste de la ciudad, y que dibuja barreras intangibles que se resisten a desaparecer (figura 5).

Pero al considerar la evolución de esas desigualdades se confirma un efecto de contagio o difusión desde los distritos más valorados de la ciudad hacia otros contiguos e, incluso, algunos periféricos, en los que reside una población con menos ingresos y cualificación. Así, mientras que en el trienio 2013-2016 el mayor encarecimiento afectó a los de Chamberí, Centro, Tetuán y Salamanca, todos localizados en el interior de la autovía M-30, en el siguiente los incrementos más acusados se desplazaron a Usera, Puente de Vallecas, Villaverde, Latina y Vicálvaro, que forman un cinturón periférico casi continuo por el sur y sureste.

Su consecuencia, reflejo de unas dinámicas donde el precio de la vivienda responde a la lógica de un mercado sin apenas regulación, es una nueva división del espacio urbano — menos evidente que la anterior- que contrapone 
dos tipos de distritos (tabla 3). Por un lado, aquellos con residentes de ingresos más elevados y mayores posibilidades de adquirir una vivienda, donde la subida del precio de venta desde 2013 ha superado la del alquiler, con todos los centrales y Moncloa-Aravaca, junto con Hortaleza y Barajas. Por otro, distritos con mayor presencia de residentes de bajos ingresos, donde el encarecimiento del alquiler superó al del precio de venta, con diferencias superiores al $20 \%$ en San Blas-Canillejas, Ciudad Lineal, Carabanchel, Latina, Villa de Vallecas, Usera o Villaverde.

En consecuencia, el arrendamiento se consolida como mecanismo extractivo, que presiona sobre los grupos sociales más vulnerables y acentúa los problemas de estrés residencial, al exigirles una proporción demasiado elevada de los ingresos familiares. También se convierte un vehículo que perpetúa los procesos de desposesión, pues entre enero de 2013 y diciembre de 2018 los lanzamientos practicados en Madrid por impago del alquiler fueron 17.446, tres cuartas partes de los 23.588 registrados en la capital.

Las claves del desigual aumento de precios son múltiples, pero se evidencian algunas regularidades significativas que los diagramas y coeficientes de determinación de la figura 6 sintetizan. Existe una elevada correlación positiva de los precios del alquiler con las rentas por habitante $\left(\mathrm{R}^{2}=0,515\right)$ y los valores catastrales de los inmuebles $\left(\mathrm{R}^{2}=0,537\right)$, por la coincidencia de los valores más altos con las áreas de elevada calidad residencial. Pero los mayores coeficientes de signo positivo son los que relacionan esos precios con la oferta turística total, según el número de plazas en hoteles y otro tipo de alojamientos contabilizadas por el registro de establecimientos turísticos de la Comunidad de Madrid $\left(\mathrm{R}^{2}=0,543\right)$ y, sobre todo, con las vinculadas a viviendas de uso turístico $\left(\mathrm{R}^{2}=0,727\right)$, controladas en buena medida por plataformas especializadas que centran su oferta en barrios centrales y espacios simbólicos de las ciudades, donde compiten con el alquiler residencial. La presencia de este tipo de alojamientos, y en concreto de una plataforma como Airbnb, ya había sido señalada como posible factor de encarecimiento y gentrificación (MartínezCaldentey et al., 2020), pero los datos aquí analizados permiten obtener un apoyo adicional y cuantificable a este tipo de argumentos. Por el contrario, la relación entre el precio del alquiler y la evolución de la población resulta de escasa significación $\left(\mathrm{R}^{2}=0,218\right)$.

Parece razonable asociar también ese incremento de precios con la presencia de inmuebles propiedad de las 22 Socimi especializadas en el alquiler residencial y de fondos de inversión, que gestionan las viviendas como activos de los que obtener unos dividendos anuales crecientes para sus accionistas o inversores y provocan un efecto de arrastre sobre los precios de su entorno. Esa relación puede resultar de especial importancia en algunos distritos periféricos donde esas entidades adquirieron inmuebles resultado de desahucios a la Sareb o diferentes bancos, lo que justificaría la escasa relación existente entre los precios en diciembre de 2019 y su evolución en el último sexenio $\left(\mathrm{R}^{2}=0,197\right)$. No obstante, la falta de información sobre la localización precisa de esa oferta inmobiliaria impide medir con precisión ese impacto, pero análisis monográficos como el 
Figura 6. Relación del alquiler por distritos de Madrid en 2019 con otros indicadores socioeconómicos
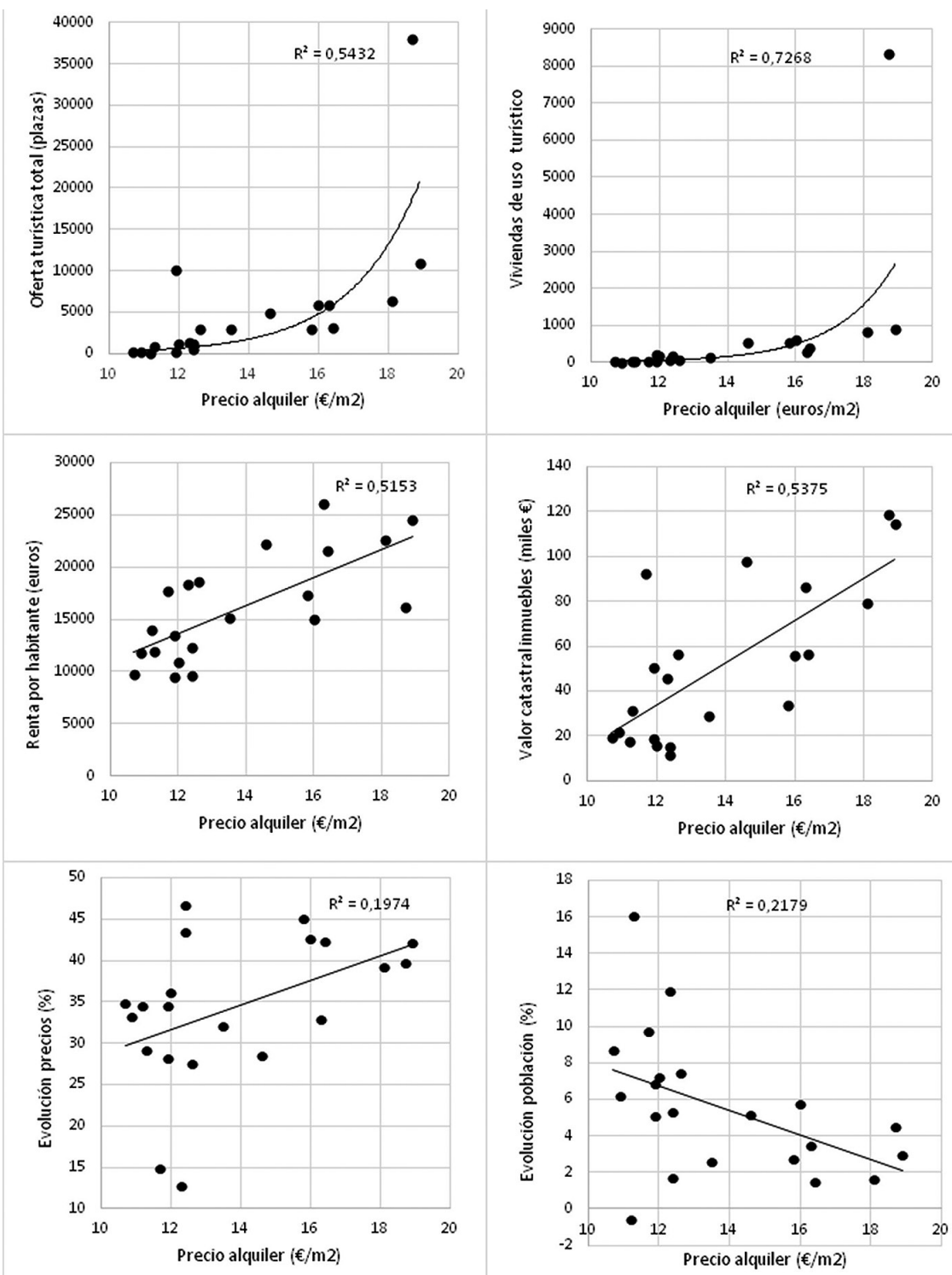

Fuente: idealista.com y elaboración propia. 
de Janoschka et al. (2019) sobre la presencia del fondo Blackstone y sus Sicimi en Madrid permiten deducir una significativa influencia, al constatar que su elevada oferta de viviendas en alquiler se concentra en algunos de esos distritos periféricos que han registrado fuertes aumentos de precio en los últimos años.

\section{Algunas conclusiones}

En resumen, tal como afirman Madden y Marcuse (2018: 30), la vivienda «plantea interrogantes sobre el poder, la desigualdad y la justicia en la sociedad capitalista», que cronifican el problema de su acceso para todos los ciudadanos, aunque con formas cambiantes a lo largo del tiempo. Tras medio siglo de retroceso constante frente al apoyo otorgado a la vivienda en propiedad, el alquiler ha ganado de nuevo importancia desde la crisis de 2007, hasta representar casi una de cada cinco viviendas ocupadas en España, con especial presencia en las grandes áreas urbanas y los espacios turísticos litorales.

Un factor esencial de esta reactivación es la creciente demanda suscitada por la dificultad de acceso al crédito hipotecario de amplios sectores con bajos ingresos y empleos precarios, lo que justifica su mayor presencia relativa entre los grupos sociales de riesgo y en aquellos barrios donde se concentran. Pero tanta o mayor importancia para ese crecimiento ha tenido la irrupción en el mercado de sociedades arrendatarias profesionales, que son propietarias de inmuebles enteros y están vinculadas de forma directa con el sector financiero. Si en el anterior ciclo inmobiliario bancos y cajas tuvieron una responsabilidad innegable como proveedores de crédito a promotores y compradores de viviendas - lo que generó una burbuja de crédito y un endeudamiento masivo que hizo inviable la continuidad del procesonuevo ciclo a los inversores institucionales. Fondos de inversión transnacionales y Socimi se implantaron en el mercado inmobiliario español a partir de 2012, adquirieron a bajo precio un gran volumen de inmuebles propiedad de bancos o la Sareb como resultado de desahucios y han destinado una buena parte de ellos al alquiler, interesados en un flujo de capital en circulación que alimente los dividendos anuales de sus inversores.

Además, el alquiler se ha convertido también en un campo de fuerzas desequilibrado, donde se contraponen actores con intereses diversos y se generan conflictos crecientes. El rápido, aunque muy desigual, encarecimiento de las rentas pagadas a los propietarios es su principal manifestación, y puede considerarse que la principal aportación del artículo es realizar ese análisis, tanto a escala interurbana como intraurbana en el caso de Madrid, para contrastar los diversos factores que inciden en esa evolución. Al correlacionar los precios en diciembre de 2019 con su evolución en el último sexenio, se constata la atonía de numerosas ciudades de tradición industrial en declive y centros de servicios de las regiones interiores, frente a procesos especulativos y precios muy elevados en grandes ciudades y núcleos turísticos, donde el concepto de burbuja vuelve a cobrar sentido, si bien en 2019 se apreciaba ya cierto agotamiento de ese aumento desbocado. Tal tendencia se ha acentuado tras el inicio de la pandemia, que 
ha paralizado en buena medida el mercado y estabilizado los precios, aunque la posible reutilización de una parte de los pisos turísticos ahora sin demanda para el alquiler residencial podría tener impacto en próximos meses al aumentar la oferta.

Al trasladar la observación al interior de la ciudad de Madrid, se confirma la localización de los mayores precios en los distritos de mayor calidad residencial y en las áreas centrales, con una relación muy estrecha con la presencia de una elevada densidad de alojamientos turísticos que ahora se cuantifica. Pero también se constata la difusión de ese rápido encarecimiento hacia algunos distritos periféricos donde otros estudios monográficos detectaron una destacada presencia de inmuebles propiedad de fondos y Socimi, aunque confirmar esta relación de manera más sólida exigirá nuevas investigaciones.

En definitiva, solo una mayor colaboración entre los estudios de geografía urbana y geografía económica puede permitir comprender mejor los procesos de mercantilización urbana que subyacen a estas tensiones y la lógica espacial profundamente desigualitaria que conllevan. No puede finalizarse el análisis sin recordar que las ciudades son también construcciones sociales y, por tanto, los actuales desequilibrios podrán reorientarse si las demandas ciudadanas y la acción política promueven, de modo inaplazable, acciones reguladoras que permitan frenar los actuales excesos, hacer más efectivo el derecho a la vivienda y avanzar en la construcción de ciudades más equitativas y habitables.

\section{Referencias bibliográficas}

Aalbers, Manuel (2016). The Financialisation of Housing: a Political Economy Approach. Londres/Nueva York: Routledge.

Alves, Pana y Urtasun, Alberto (2019). «Evolución reciente del mercado de la vivienda en España». Boletín Económico del Banco de España, 2, 1-11. Recuperado de $<$ https://www.bde.es/f/webbde/SES/Secciones/Publicaciones/InformesBoletinesRevistas/ArticulosAnaliticos/19/T2/descargar/Fich/be1902-art9.pdf>.

Burriel, Eugenio (2008). «La década prodigiosa del urbanismo español (1997-2006)». Scripta Nova. Revista Electrónica de Geografía y Ciencias Sociales, XII, 270 (64). Recuperado de <http://www.ub.edu/geocrit/sn/sn-270/sn-270-64.htm>.

- (2014). «El estallido de la burbuja inmobiliaria y sus efectos en el territorio». En: Albertos, J. M. y Sánchez, J. L. (coords.). Geografía de la crisis económica en España. Valencia: Publicacions Universitat de València, 101-140.

Chesnais, Michel (2003). «La teoría del régimen de acumulación financiarizado: contenido, alcance e interrogantes». Revista de Economía Crítica, 1, 37-72. Recuperado de <http:/www.revistaeconomiacritica.org/sites/default/files/revistas/n1/4_teoria_regimen.pdf>.

Christophers, Brett (2011). "Revisiting the urbanization of capital». Annals of the Association of American Geographers, 101 (6), 1.347-1.364.

Christopherson, Susan; Martin, Ron y Pollard, Jane (2013). "Financialisation: roots and repercussions». Cambridge Journal of Regions, Economy and Society, 6 (3), 351-357.

DAHER, Antonio (2013). «El sector inmobiliario y las crisis económicas». EURE. Revista Latinoamericana de Estudios Urbano Regionales, 39 (118), 47-76. Recuperado de <http://www.eure.cl/index.php/eure/article/view/468/613>. 
EPRA (2019). Global REIT Survey 2019. Bruselas: European Public Real Estate Association.

FARHA, Leila (2017). Informe de la relatora especial sobre una vivienda adecuada como elemento integrante del derecho a un nivel de vida adecuado y sobre el derecho de no discriminación a este respecto. Nueva York: Naciones Unidas, Consejo de Derechos Humanos, 1-25.

Fondo Monetario Internacional (2019). Global Real House Price Index. Washington: FMI. Recuperado de <https://www.imf.org/external/research/housing/>.

Fox Goтнам, Kevin (2013). "Creating liquidity of spatial fixity: the secondary circuit of capital and the subprime mortgage crisis». International Journal of Urban and Regional Research, 33 (2), 355-371.

Gabarre, Manuel (2019). Tocar fondo. La mano invisible detrás de la subida del alquiler. Madrid: Traficantes de Sueños.

García Montalvo, José (2019). «Retos del mercado del alquiler en España». Cuadernos de Información Económica, Funcas, 269, 1-11.

Harvey, David (1985). The Urbanization of Capital. Studies on the Story and Theory of Capitalist Urbanization. Baltimore: Johns Hopkins University Press.

- (2007). «La acumulación por desposesión». En: Harvey, David. El nuevo imperialismo. Madrid: Akal, 111-140.

Janoschka, Michael; Alexandri, Georgia; Orozco, Hernán y Vives-Miró, Sonia (2019). «Tracing the socio-spatial logics of transnational landlords' real estate investment: Blackstone in Madrid». European Urban and Regional Studies, 20 de enero de 2019, 1-17.

Lapavitsas, Costas (2016). Beneficios sin producción. Cómo nos explotan las finanzas. Madrid: Traficantes de Sueños.

Lefebvre, Henri (1970). La révolution urbaine. París: Éditions Gallimard.

- (2013). La producción del espacio. Madrid: Capital Swing [original, 1974].

Lois, Rubén; Piñeira, M. a José y Vives-Miró, Sonia (2016). «El proceso urbanizador en España (1990-2014): una interpretación desde la geografía y la teoría de los circuitos de capital». Scripta Nova, xx, 539, 1-27. Recuperado de <http://www. ub.edu/geocrit/sn/sn-539.pdf>.

López, Isidre y RodríGuez, Emmanuel (2010). Fin de ciclo. Financiarización, territorio y sociedad de propietarios en la onda larga del capitalismo hispano (1959-2010). Madrid: Traficantes de Sueños.

López Rodríguez, David y Matea, M.a de los Llanos (2019). «Evolución reciente del mercado del alquiler de vivienda en España». Boletín Económico - Banco de España, 3.

Madden, David y Marcuse, Peter (2018). En defensa de la vivienda. Madrid: Capitán Swing.

Martínez-Caldentey, M.a Antonia; Murray, Iván y Blázquez-Salom; Macià (2020). «En la ciudad de Madrid todos los caminos conducen a Airbnb». Investigaciones Turísticas, 19, 1-27.

Mattos, Carlos de (2018). «Crecimiento urbano financiarizado». Documentos de Trabajo IEUT, 4, 1-30. <https://doi.org/10.13140/RG.2.2.24420.42882>

MéNDEZ, Ricardo (2018). La telaraña financiera. Una geografía de la financiarización y sus crisis. Santiago de Chile/Barcelona: RIL Editores.

- (2019). Ciudades en venta. Estrategias financieras y nuevo ciclo inmobiliario en España. Valencia: PUV. 
NAREDO, José Manuel (2009). «La cara oculta de la crisis. El fin del boom inmobiliario y sus consecuencias». Revista de Economía Crítica, 7, 313-340.

Observatorio de Vivienda y Suelo (2019). Boletín especial. Alquiler residencial, 2019. Madrid: Ministerio de Fomento.

Palomera, Jaime (2019). «De l'estafa hipotecària a l'estafa del lloguer». Barcelona Metropolis, 112, 14-19.

Pike, Andy y Pollard, Jane (2010). «Economic geographies of financialization». Economic Geography, 86 (1), 29-51.

RolNiK, Raquel (2018). La guerra de los lugares. La colonización de la tierra y la vivienda en la era de las finanzas. Barcelona: Descontrol.

Theodore, Nick; Peck, Jamie y Brenner, Neil (2009). «Urbanismo neoliberal: la ciudad y el imperio de los mercados». Temas Sociales, 1-11. Recuperado de <http:// www.sitiosur.cl/detalle-de-la-publicacion/?PID=3532>.

Vinuesa, Julio (2013). El festín de la vivienda. Auge y caída del negocio inmobiliario en España. Madrid: Díaz \& Pons.

Vives-Miró, Sonia y Rullán, Onofre (2014). «La vivienda en el tránsito de la reproducción ampliada del capital a la acumulación por desposesión en España». XII Coloquio y Trabajos de Campo del Grupo de Geografía Urbana (AGE): Territorios inconclusos y sociedades rotas, 1-15. 
